\begin{tabular}{|c|l|}
\hline Title & Delamination structure imaged in the source area of the 1982 Urakawa oki earthquake \\
\hline Author(s) & $\begin{array}{l}\text { Murai, Y oshio; A kiyama, Satoshi; Katsumata, Kei; Takanami, Tetsuo; Y Yamashina, Tadashi; Watanabe, Tomoki; Cho, } \\
\text { Ikuo; Tanaka, Masay uki; Kuwano, A sako; Wada, Naoto; Shimamura, Hideki; Furuya, Itsuo; Zhao, Dapeng; Sanda, } \\
\text { Ryohei }\end{array}$ \\
\hline Citation & $\begin{array}{l}\text { Geophysical Research Letters, 30(9), 1490 } \\
\text { https://doi.org/10.1029/2002GL016459 }\end{array}$ \\
\hline Issue Date & 2003-05-14 \\
\hline Doc URL & http://hdl.handle.net/2115/17236 \\
\hline Rights & $\begin{array}{l}\text { An edited version of this paper was published by A GU /Copyright 2003, A merican Geophysical Union, } \\
\text { GEOPHY SICAL RESEARCH LETTERS }\end{array}$ \\
\hline Type & article (author version) \\
\hline File Information & GRL30-9.pdf \\
\hline
\end{tabular}

Instructions for use 


\section{Delamination structure imaged in the source area of the 1982 Urakawa-oki earthquake}

Yoshio Murai, ${ }^{1}$ Satoshi Akiyama, ${ }^{1}$ Kei Katsumata, ${ }^{1}$ Tetsuo Takanami, ${ }^{1}$ Tadashi Yamashina, ${ }^{1,2}$ Tomoki

Watanabe, ${ }^{1,3}$ Ikuo Cho, ${ }^{1,4}$ Masayuki Tanaka, ${ }^{5}$ Asako Kuwano, ${ }^{1,6}$ Naoto Wada, ${ }^{1}$ Hideki Shimamura, ${ }^{1}$ Itsuo Furuya, ${ }^{5}$ Dapeng Zhao, ${ }^{7}$ and Ryohei Sanda ${ }^{7}$

${ }^{1}$ Institute of Seismology and Volcanology, Graduate School of Science, Hokkaido University, Sapporo, Japan.

${ }^{2}$ Now at National Research Institute for Earth Science and Disaster Prevention, Tsukuba, Japan.

${ }^{3}$ Now at Japan Marine Science and Technology Center, Yokohama, Japan.

${ }^{4}$ Now at Geo-Research Institute, Osaka, Japan.

${ }^{5}$ Seismological and Volcanological Department, Japan Meteorological Agency, Tokyo, Japan.

${ }^{6}$ Now at Research Center for Prediction of Earthquakes and Volcanic Eruptions, Graduate School of Science, Tohoku University, Sendai, Japan.

${ }^{7}$ Geodynamics Research Center, Ehime University, Matsuyama, Japan.

Y. Murai, S. Akiyama, K. Katsumata, T. Takanami, N. Wada, and H. Shimamura, Institute of Seismology and Volcanology, Graduate School of Science, Hokkaido University, N-10 W-8, Kita-ku, Sapporo 060-0810, Japan. (murai@eos.hokudai.ac.jp)

T. Yamashina, National Research Institute for Earth Science and Disaster Prevention, 3-1 Tennodai,Tsukuba, Ibaraki 305-0006, Japan.

T. Watanabe, Japan Marine Science and Technology Center, 3173-25 Showa-machi, Kanazawa-ku, Yokohama 236-0001, Japan.

I. Cho, Geo-Research Institute 4-3-2 Itachibori, Nishi-ku, Osaka 550-0012, Japan.

M. Tanaka and I. Furuya, Seismological and Volcanological Department, Japan Meteorological Agency, 1-3-4 Otemachi, Chiyoda-ku, Tokyo 100-8122, Japan.

A. Kuwano, Research Center for Prediction of Earthquakes and Volcanic Eruptions, Graduate School of Science, Tohoku University, Aza Aoba, Aramaki, Aoba-ku, Sendai 980-8578, Japan.

D. Zhao and R. Sanda, Geodynamics Research Center, Ehime University, Matsuyama 790-8577, Japan. 
Abstract. The Kuril arc collides with the northeast Japan arc in the southern part of Hokkaido, Japan. 3-D tomographic inversion of data from a dense network of sensitive ocean-bottom seismographs and land stations has allowed imaging of previously unseen details of the arc-arc collision structure. A low velocity body dips gently southwestward, at depths of 35 to $45 \mathrm{~km}$, from east of the Hidaka Mountains to the source area of the 1982 Urakawa-oki destructive earthquake (Ms 6.8). The low velocity body is the lower half of the lower crust of the Kuril arc, which must have been delaminated by the collision. We believe that the continuing collision of the delaminated lower crust with the northeast Japan arc resulted as an episode of aseismic slow slip prior to the 1982 Urakawa-oki earthquake as well being the reason for the high seismic activity in this region.

\section{Introduction}

Arc-arc collisions are important process in the transformation of island-arc crust to new continental crust [Kimura, 1996]. In the southern Hokkaido region of Japan, the Kuril arc has been colliding with the northeast Japan arc since middle Miocene [Kimura, 1996], resulting in the uplift of the Hidaka Mountains behind the Hidaka Main Thrust. Petrologic and deformational studies on the surface geology show that the relatively pristine lower crustal rocks of the Kuril arc have been exposed in the Hidaka Mountains by overthrusting of the Kuril arc [Komatsu et al., 1983; Osanai et al., 1986]. Seismic tomographic and exploration studies confirm that the Kuril arc is obducted towards the west [Takanami, 1982; Miyamachi and Moriya, 1984; Iwasaki et al., 1998; Tsumura et al., 1999]. The west-southwestward motion of the Kuril arc is also confirmed by GPS data [Mazzotti et al., 2000]. However the spatial resolution of the previous tomographic studies is rather poor for the deep crustal and uppermost mantle structure, especially in the offshore area. Recently Tsumura et al. [1999] used data from seismic reflection surveys to show that the lower crust of the Kuril arc is delaminated at a depth of $23-33 \mathrm{~km}$ in the eastern side of the Hidaka Mountains and that the lower part is descending westward. However their data do not allow adequate spatial coverage. It is necessary to image the 3-D structure in order to clarify the collision tectonics. 
It is also important in order to understand the patterns of earthquake occurrence. Around the southwestern foot of the Hidaka Mountains, the seismic activity is high and the earthquakes occur to a maximum depth of $65 \mathrm{~km}$, which corresponds to the upper boundary of the subducting Pacific plate [Moriya et al., 1997, 1998]. This suggests the materials are still brittle even in such a deep region. In addition, destructive earthquakes such as the 1982 Urakawa-oki earthquake (Ms 6.8) occurred in this area. Arc-arc collision is also thought to be responsible for the earthquake occurrence [Moriya et al., 1997, 1998] but this issue has remained a matter of speculation. Here we present a higher resolution 3-D arc-arc collision structure inferred from a tomographic inversion of seismic travel time data and discuss its implications for earthquake occurrence.

\section{Data and Methods}

In 1999, we conducted observations of microearthquakes with a dense network of 87 land stations and 21 pop-up type ocean-bottom seismographs (OBSs) (Figure 1 (left)). We continued observation with this land array for about 2 years, while the OBSs had recording periods of about either 4 or 8 weeks in 1999 . We used only events recorded for the 8 weeks of the OBS deployment to obtain a homogeneous data set for the tomographic inversion.

We first determined the hypocenters by using a maximum-likelihood estimation algorithm with a Bayesian approach [Hirata and Matsu'ura, 1987] to analyze the arrival time data from the land and OBS arrays. We removed travel time delays due to unconsolidated sediments beneath the OBS stations. These station corrections were estimated from travel time differences between direct $P$ and $P$-S basement conversions, assuming sediment $P$ - and $S$ - wave velocities of 2.0 and $0.725 \mathrm{~km} / \mathrm{s}$, respectively [Iwasaki et al., 1991]. We did not apply station corrections for the land stations because they are located on bedrock. We used the laterally homogeneous $P$-wave velocity structure Models $\mathrm{L}$ and $\mathrm{O}$ in Figure 1 (right top) for land and OBS arrays, respectively, and assumed a $P$ - to $S$-wave velocity ratio of 1.73 . Model $L$ is the velocity structure routinely used for locating earthquakes with the seismic network operated by Hokkaido 
University. Model $\mathrm{O}$ is based on the velocity structure determined from a seismic refraction experiment in the southwest Hokkaido region [Asano et al., 1979]. Because crustal structure deeper than $15 \mathrm{~km}$ depth was not estimated, we sought the crustal thickness and $P$-wave velocity of the mantle which minimized travel time residuals in trial hypocenter determinations using only the OBSs data. We determined the hypocenters of 420 events with the land array for the 8 weeks of the OBS deployment, while we obtained 424 hypocenters from the OBS array (Figure 1 (right bottom)). As 148 of them are determined by both arrays, we relocated these events by merging the arrival data and using the laterally homogeneous velocity structure Model C in Figure 1 (right top), which is an 'average' of Models $\mathrm{L}$ and $\mathrm{O}$ and minimizes travel time residuals. The combined land-OBS array provides a favorable station geometry for this study.

We selected 488 from 696 hypocenters in Figure 1 (right bottom) for the tomographic inversion. The selected earthquakes have magnitudes larger than 1.5 and those hypocenters are determined from at least 5 arrival times. Moreover we excluded hypocenters with negative depth and those shallower than $5.811 \mathrm{~km}$, the deepest OBS, for the earthquakes detected by the OBS array. We used 7,657 P arrival times with residuals less than $1.5 \mathrm{~s}$ for the velocity structure models in Figure 1 (right top), to determine the hypocenters and estimated $P$-wave velocity structure.

We used the seismic tomography method of Zhao et al. [1992, 1994]. In this method, correction terms for the source and velocity model parameters are estimated iteratively, by minimizing all travel time residuals in a least squares sense. We iterated the inversion until the reduction in the root-mean-square (rms) travel time residuals was less than 0.1 s. For the $3-\mathrm{D}$ inversion, the conjugate gradient $(\mathrm{CG})$ method and LSQR algorithm [Paige and Saunders, 1982] are used to solve the large and sparse observation equations that relate the data to the source and medium parameters. A pseudo-bending method [Zhao et al., 1992; Koketsu and Sekine, 1998] is used to trace seismic rays.

The model spanned the latitude range of $40.6^{\circ} \mathrm{N}-43.4^{\circ} \mathrm{N}$ and the longitude range of $141^{\circ} \mathrm{E}-146.4^{\circ} \mathrm{E}$ with a grid interval of $0.2^{\circ}$. We placed the shallowest layer of the grid at a depth of $9 \mathrm{~km}$, which is $3.189 \mathrm{~km}$ 
below the deepest OBS, to take heterogeneity of the sedimentary layer into account. The other layers of the grid spanned the depth range from 15 to $105 \mathrm{~km}$ with an interval of $10 \mathrm{~km}$. As the initial model we assumed the laterally homogeneous velocity structure Model C in Figure 1 (right top), where the velocities at the grid points are shown by dots. The station corrections for the OBS data were the same as those used in the hypocenter determination.

The rms of the travel time residuals was reduced from $1.02 \mathrm{~s}$ to $0.55 \mathrm{~s}$ after 3 iterations of the inversion. We performed a checkerboard resolution test [e.g. Inoue et al., 1990] in order to check the reliability of the estimated parameters. In this test we used a velocity perturbation of 10 per cent with a checkerboard pattern that has the same sizes as the grid intervals and then inverted the artificial travel time data calculated for the test model. The original checkerboard patterns were reconstructed fairly well in the area shown in Figure 2 and for depths shallower than $55 \mathrm{~km}$.

\section{Results}

From the tomographic images, distinct low-velocity anomalies are detected extending from the western side to the central part of the Hidaka Mountains in the depth interval from 9 to $25 \mathrm{~km}$ (Figures 2(a) and 2(b)). These low-velocity anomalies run parallel to the Hidaka Mountains from $42^{\circ} \mathrm{N}$ to $42.8^{\circ} \mathrm{N}$. Highvelocity anomalies are found just beneath the crest of the Hidaka Mountains (Figure 2(a)). They stretch in the NW-SE direction so as to overlie the low-velocity anomalies referred to above. At depths of 35 to 45 km, there are low-velocity anomalies beneath the Hidaka Mountains (Figures 2(c) and 2(d)).

Figure 3 shows the vertical cross section along the line A-B in Figure 2(a). This direction is almost perpendicular to the axis of the Hidaka Mountains and the line crosses the aftershock region of the 1982 Urakawa-oki earthquake [Moriya et al., 1998]. A 5.8-6.0 km/s body, whose velocity is consistent with that obtained by seismic refraction experiments [Iwasaki et al., 1998], dips eastward from west of the Hidaka Mountains. It is considered to be the crust of the northeast Japan arc. A $6.7-7.4 \mathrm{~km} / \mathrm{s}$ body is found just beneath the crest of the Hidaka Mountains with velocity in good agreement with that of the lower crust in 
central Hokkaido as determined by seismic refraction experiments [Iwasaki et al., 1998]. It is considered to be the Kuril arc obducted towards the west. These results are consistent with those obtained by previous tomographic studies [Takanami, 1982; Miyamachi and Moriya, 1984].

Our new finding is a $6.9-7.4 \mathrm{~km} / \mathrm{s}$ body at depths of 35 to $45 \mathrm{~km}$, dipping gently southwestward from east of the Hidaka Mountains to the source area of the 1982 Urakawa-oki earthquake [Miyamachi and Moriya, 1987; Suzuki and Motoya, 1983]. Its velocity is also consistent with that of the lower crust of the Kuril arc and the depth corresponds to the crustal laminations characteristic of the lower crust [Iwasaki et al., 1998]. Therefore we consider it delaminated lower crust of the Kuril arc. The line A-B almost coincides with the survey lines of the seismic reflection experiments by Tsumura et al. [1999] on land and thus we concur with their interpretation that the lower crust of the Kuril arc is delaminated by the collision. Here we find that the lower part of the Kuril arc lower crust extends beneath the sea and that the 1982 Urakawa-oki earthquake occurred near its tip. Our ability to characterize this new structure arises from our use of both land and OBS array data.

\section{Discussion}

We propose the collision model shown in Figure 3. If we assume the Moho discontinuity to be the $7.6 \mathrm{~km} / \mathrm{s}$ contour, the depth is $20 \mathrm{~km}$ and $30 \mathrm{~km}$ at the east and west of Hokkaido Island, respectively, which is consistent with the result of Miyamachi et al. [1994]. In this figure the boundary between the Kuril arc and the northeast Japan arc is shown by a broken line, which is taken to be the boundary between the high and low velocity anomalies at depths shallower than $30 \mathrm{~km}$ together with the plane where velocity inversion occurs at around $30 \mathrm{~km}$ depth and the $7.4 \mathrm{~km} / \mathrm{s}$ contour at greater depths. The length of the lower part of the delaminated Kuril arc lower crust is about 50km, which is comparable to the total crustal shortening length between the two island-arcs evaluated from geological data [Ito et al., 2001]. The upper boundary of the subducting Pacific plate is assumed to be the upper seismic plane of the double-planed deep seismic zone, which is estimated by expressing the 2-D depth distribution of the hypocenters in the upper seismic plane, 
determined from land array data as a power series function of latitude and longitude, similar to the procedure by Miyamachi et al. [1994]. Its depth is almost the same as their estimates.

The faulting mechanism of the 1982 Urakawa-oki earthquake shows a thrust type solution with a compressional axis in a NE-SW direction [Takeo et al., 1983; Moriya et al., 1983]. In addition, we estimated the direction of maximum compression by using the stress tensor inversion method of Horiuchi et al. [1995] and the focal mechanism solutions of many microearthquakes. They show NE-SW direction in the western side of the Hidaka Mountains (bars in Figures 2 and 3). The direction of the earthquakegenerating stress is consistent with our collision model. The delaminated lower crust appears to reach a depth close to the upper boundary of the subducting Pacific plate in this region. All the earthquake hypocenters determined by the dense network of the land stations are projected in Figures 2 and 3. On the whole, the distribution of the earthquakes is concentrated in the region close to the tip of the subducting lower crust of the Kuril arc. It is plausible that compressional stress is accumulated there due to the collision and is released by earthquake faulting near the structural boundary. Thus our model would explain why the seismicity is high even in such a deep crust in this region. The 1982 Urakawa-oki earthquake ruptured the region shallower than the subducting lower crust. However an aseismic slow slip occurred on the deeper extension of the co-seismic fault plane about 3 years before the earthquake [Tada, 1987]. We infer that the slow pre-slip occurred at the front of the subducting lower crust of the Kuril arc.

Acknowledgments. We thank the captains and crews of the R/V Kofu Maru of the Hakodate Marine Observatory and the M/V Kaiko Maru No.5 of Offshore Operation Co., Ltd. for their cooperation during deployment and recovery of OBSs. We thank H. Negishi for offering valuable comments on the tomographic inversion method, and A. T. Linde and S. I. Sacks for improvement of the English in the text.

\section{References}


Asano, S., N. Den, H. Hotta, T. Yoshii, Y. Ichinose, N. Sakajiri, and T. Sasatani, Seismic refraction and reflection measurements around Hokkaido part 2. Crustal structure of the continental slope off Hidaka, $J$. Phys. Earth, 27, 497-509, 1979.

Hirata, N., and M. Matsu'ura, Maximum-likelihood estimation of hypocenter with origin time estimated using nonlinear inversion technique, Phys. Earth Planet. Inter., 47, 50-61, 1987.

Horiuchi, S., G. Rocco, and A. Hasegawa, Discrimination of fault planes from auxiliary planes based on simultaneous determination of stress tensor and a large number of fault plane solutions, J. Geophys. Res., 100, 8327-8338, 1995.

Inoue, H., Y. Fukao, K. Tanabe, and Y. Ogata, Whole mantle P-wave travel time tomography, Phys. Earth Planet. Inter., 59, 294-328, 1990.

Ito, T., T. Kazuka, K. Suzuki, T. Ikawa, H. Sato, T. Iwasaki, N. Hirata, and T. Ikawa, Total crustal shortening of the Hidaka Collision Zone, Hokkaido, Japan, Abstracts Jpn. Earth Planet. Sci. Joint Meet., Sz-016, 2001.

Iwasaki, T., N. Hirata, T. Kanazawa, T. Urabe, Y. Motoya, and H. Shimamura, Earthquake distribution in the subduction zone off eastern Hokkaido, Japan, deduced from ocean-bottom seismographic and land observations, Geophys. J. Int., 105, 693-711, 1991.

Iwasaki, T., O. Ozel, T. Moriya, S. Sakai, S. Suzuki, G. Aoki, T. Maeda, and T. Iidaka, Lateral structural variation across a collision zone in central Hokkaido, Japan, as revealed by wide-angle seismic experiments, Geophys. J. Int., 132, 435-457, 1998.

Kimura, G., Collision orogeny at arc-arc junctions in the Japanese Islands, The Island Arc, 5, 262-275, 1996.

Koketsu, K., and Sekine, S., Pseudo-bending method for three-dimensional seismic ray tracing in a spherical earth with discontinuities, Geophys. J. Int., 132, 339-346, 1998. 
Komatsu, M., S. Miyashita, J. Maeda, Y. Osanai, and T. Toyoshima, Disclosing of a deepest section of continental type crust upthrust as the final event of collision of arcs in Hokkaido, in Accretion Tectonics in the Circum-Pacific Regions, edited by M. Hashimoto, and S. Ueda, pp.149-165, Terrapub, Tokyo, 1983.

Mazzotti, S., X. Le Pichon, and P. Henry, Full interseismic locking of the Nankai and Japan-west Kurile subduction zones: An analysis of uniform elastic strain accumulation in Japan constrained by permanent GPS, J. Geophys. Res., 105, 13159-13177, 2000.

Miyamachi, H., and T. Moriya, Velocity structure beneath Hidaka Mountains in Hokkaido, Japan, J. Phys. Earth, 32, 13-42, 1984.

Miyamachi, H., and T. Moriya, Velocity structure and aftershock distribution of the 1982 Urakawa-oki earthquake., J. Phys. Earth, 35, 309-326, 1987.

Miyamachi, H., M. Ksahara, S. Suzuki, K. Tanaka, and A. Hasegawa, Seismic velocity structure in the crust and upper mantle beneath northern Japan, J. Phys. Earth, 42, 269-301, 1994.

Moriya, T., H. Miyamachi, and S. Katoh, Spatial distribution and mechanism solutions for foreshocks, mainshock and aftershocks of the Urakawa-oki earthquake of March 21, 1982 (in Japanese), Geophys. Bull. Hokkaido University, 42, 191-213, 1983.

Moriya, T., H. Miyamachi, O. Ozel, N. Ozel, T. Iwasaki, and M. Kasahara, Collision structure and seismotectonics of the Hidaka Mountains, Hokkaido, Japan, (in Japanese), Struct. Geol., 42, 15-30, 1997.

Moriya, T., H. Okada, T. Matsushima, S. Asano, T. Yoshii, and A. Ikami, Collision structure in the upper crust beneath the southwestern foot of the Hidaka Mountains, Hokkaido, Japan as derived from explosion seismic observations, Tectonophysics, 290, 181-196, 1998.

Osanai, Y., K. Arita, and M. Bamba, M., P-T conditions of granulite-facies rocks from the Hidaka metamorphic belt, Hokkaido, J. Geol. Soc. Jpn., 92, 793-808, 1986.

Paige, C. C., and Saunders, M. A. LSQR: An algorithm for sparse linear equations and sparse least squares, Assoc. Comput. Mach. Trans. Math. Software, 8, 43-71, 1982. 
Suzuki, S., and Y. Motoya, Time variation of the seismic activity before and after the 1982 earthquake off Urakawa, Hokkaido (in Japanese), in General Report on the Urakawa-Oki, Japan, Earthquake, of March 21, 1982, edited by Y. Sakai, pp.57-69, Kosoku Insatsu, Sapporo, 1983.

Tada, T., Fault model of the 1982 Urakawa-oki earthquake and its tectonic significance (in Japanese), Zisin 2, 40, 27-37, 1987.

Takanami, T., Three-dimensional seismic structure of the crust and upper mantle beneath the orogenic belts in southern Hokkaido, Japan, J. Phys. Earth, 30, 87-104, 1982.

Takeo, M., M. Kasahara, and K. Abe, Focal process of the Urakawa-oki earthquake of March 21, 1982 (in Japanese), in General Report on the Urakawa-Oki, Japan, Earthquake, of March 21, 1982, edited by Y. Sakai, pp.1-11, Kosoku Insatsu, Sapporo, 1983.

Tsumura, N., H. Ikawa, T, Ikawa, M. Shinohara, T. Ito, K. Arita, T. Moriya, G. Kimura, and T. Ikawa, Delamination-wedge structure beneath Hidaka collision zone, central Hokkaido, Japan inferred from seismic reflection profiling, Geophys. Res. Lett., 26, 1057-1060, 1999.

Zhao, D., A. Hasegawa, and S. Horiuchi, Tomographic imaging of $P$ and $S$ wave velocity structure beneath northeastern Japan, J. Geophys. Res., 97, 19909-19928, 1992.

Zhao, D., A. Hasegawa, and H. Kanamori, Deep structure of Japan subduction zone as derived from local, regional, and teleseismic events, J. Geophys. Res., 99, 22313-22329, 1994.

Figure 1. (Left) Distribution of seismographic stations used in this study. Circles and boxes represent OBS sites with recording periods of 4 and 8 weeks, respectively. Inset, regional map showing the location of the study area. Thin lines show the major plate boundaries. Abbreviations: KA, Kuril Arc; NJA, Northeast Japan Arc; EP, Eurasian Plate; PP, Pacific Plate; and PSP, Philippine Sea Plate. (Right top) $P$-wave velocity structure models for hypocenter determination (Models L, O and C) and velocities at grid points of the initial model for the tomographic inversion (dots of Model C). (Right bottom) Distribution of epicenters 
determined in this study. Closed circles represent the epicenters of the events used in the tomographic inversion. Thin line shows the Japan and Kuril Trenches.

Figure 2. Estimated seismic velocity images at (a) 15-, (b) 25-, (c) 35-, and (d) 45- km depths. The amplitude of velocity perturbation from the initial model is distinguished by color. Only results with good resolution are plotted. Thick solid line A-B in (a) indicates the location of the cross section displayed in Figure 3. Open circles are epicenters, within a 10-km depth range of the slice, determined by the dense network of land stations for the whole observation period. The maximum compressional axes estimated from the focal mechanism solutions of these earthquakes are shown by bars projected onto the horizontal plane. They are plotted so that the length coincides with that of the reference bar at the base of the figure when the maximum compressional stress is purely horizontal. Location of the Hidaka Main Thrust (HMT) is shown. A star and a thin line indicate the epicenter [Suzuki and Motoya, 1983] and aftershock region [Moriya et al., 1998] of the 1982 Urakawa-oki earthquake, respectively.

Figure 3. Vertical profile of the estimated seismic velocity model for the cross section along the line A-B in Figure 2(a). Only results with good resolution are plotted. The origin of the abscissa represents the west coast line of Hokkaido Island. Open circles are the hypocenters that lie within $10 \mathrm{~km}$ of the vertical plane. The maximum compressional axes estimated from the focal mechanism solutions of these earthquakes are shown by bars projected onto the vertical plane. They are plotted so that the length coincides with that of the reference when the axis is parallel to this vertical plane. The epicenter [Suzuki and Motoya, 1983] and aftershock region [Miyamachi and Moriya, 1987] of the 1982 Urakawa-oki earthquake are shown projected by a star and thick gray lines, respectively. Geological interpretation is superimposed. We assume the Moho discontinuity to be the $7.6 \mathrm{~km} / \mathrm{s}$ contour. A broken line shows the inferred boundary between the two islandarcs. The upper boundary of the subducting Pacific plate is estimated from the 2-D depth distribution of the hypocenters in the upper seismic plane of the double-planed deep seismic zone. A thick solid line and a triangle at the top represent the locations of the land area and the Hidaka Mountains, respectively. 


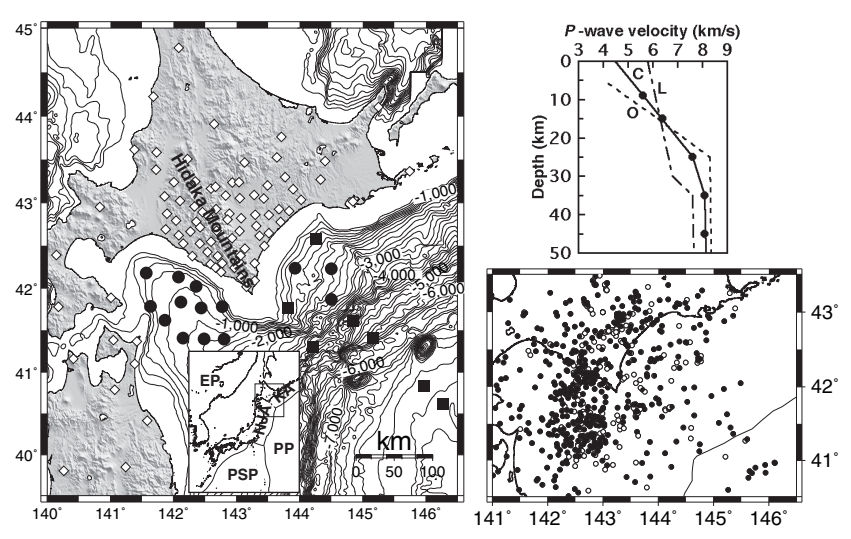

Figure 1. 

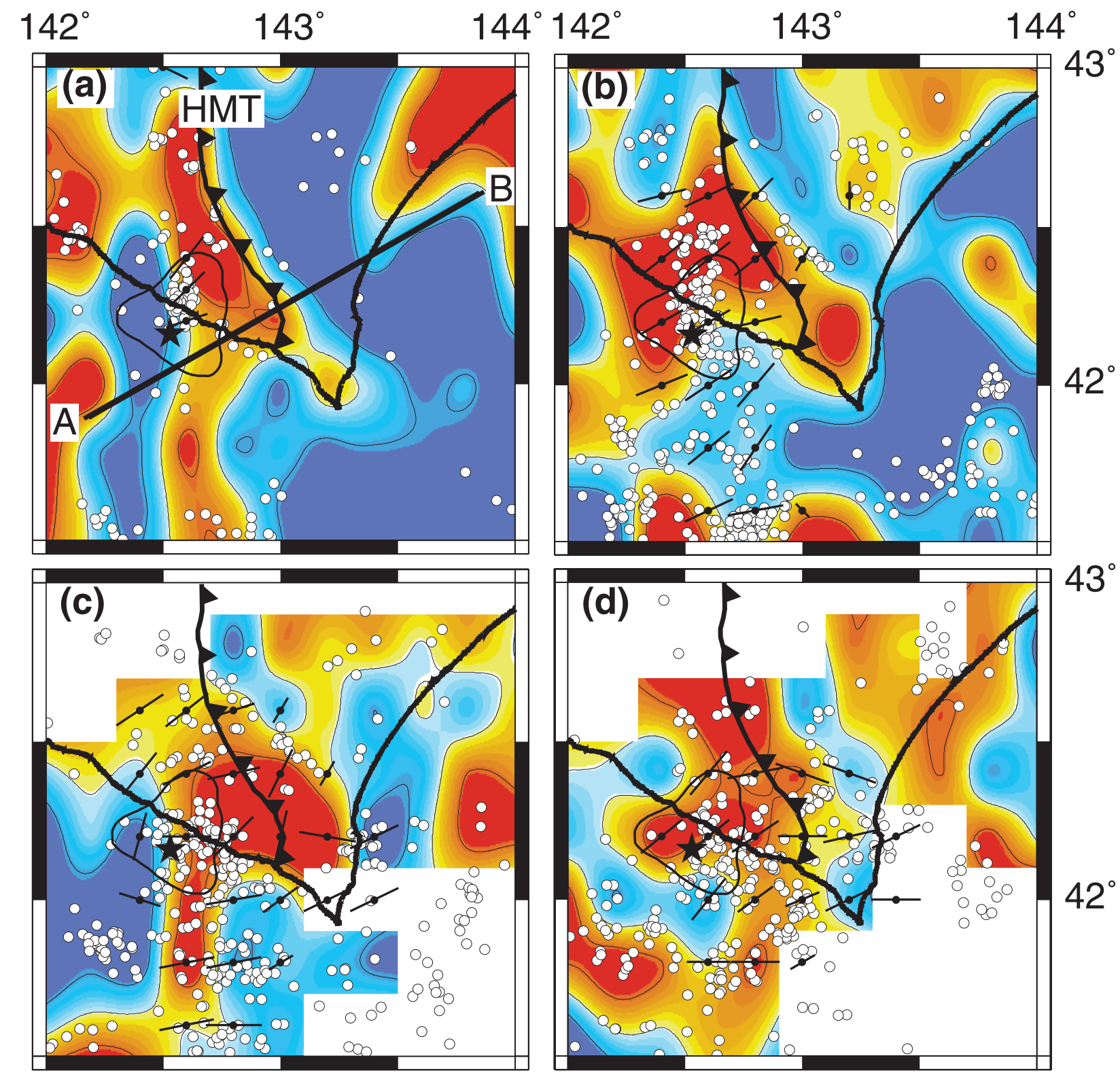

$-10 \% \quad-5 \% \quad 0 \% \quad 5 \% \quad 10 \%$

Figure 2. 


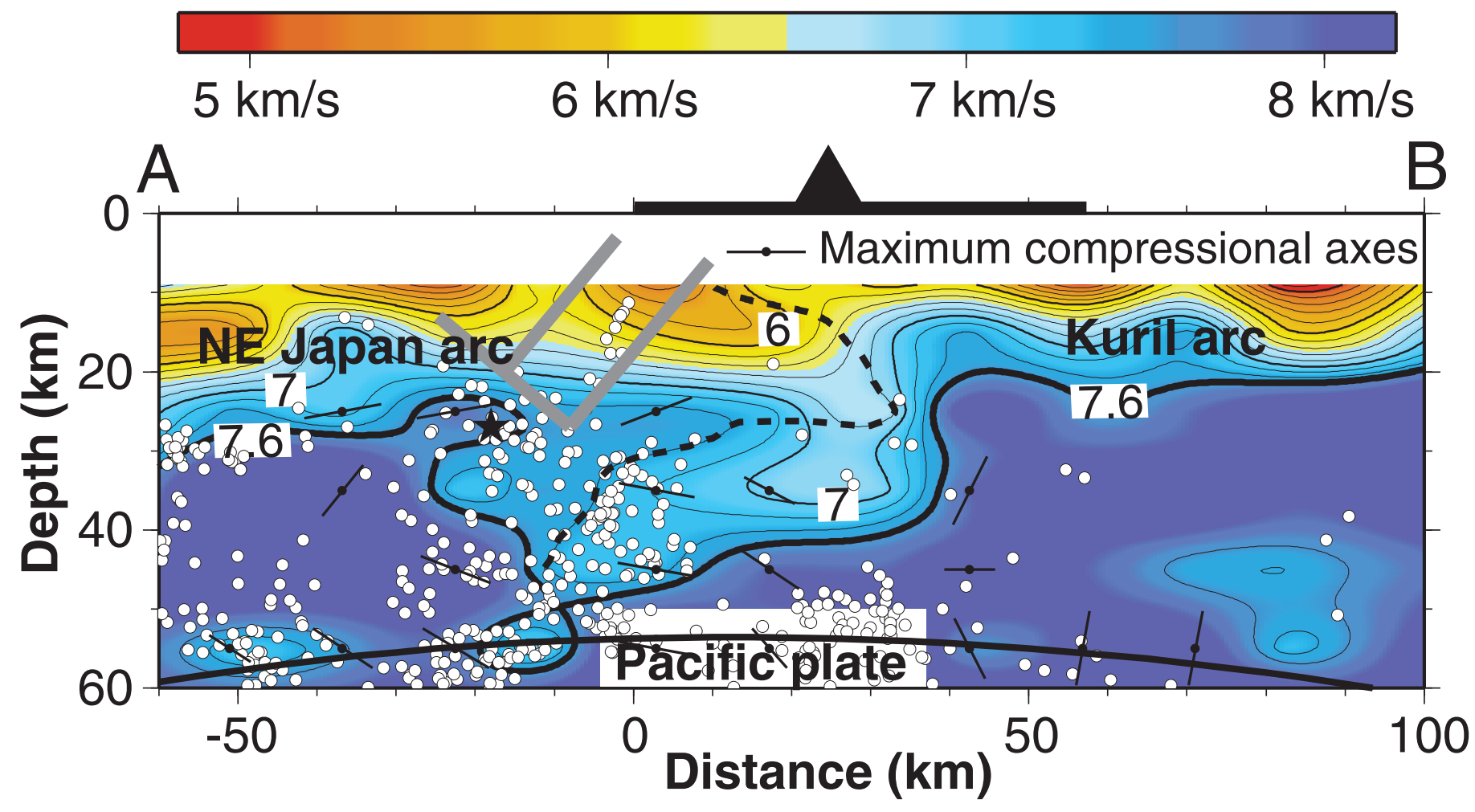

Figure 3. 